\title{
CORRECTION
}

\section{Correction to: Predictors of Satisfaction with Autism Treatment Services During COVID-19}

\author{
Emily F. Ferguson ${ }^{1}$ (D) Maria Jimenez-Muñoz ${ }^{1} \cdot$ Harrison Feerst ${ }^{1} \cdot$ Ty W. Vernon $^{1}$
}

Published online: 5 October 2021

๑) Springer Science+Business Media, LLC, part of Springer Nature 2021

\section{Correction to: Journal of Autism and Developmental Disorders https://doi.org/10.1007/s10803-021-05232-0}

In the original article there is an error in the Introduction Section (Sentence 2 of the Introduction after the Abstract) and it has been corrected in this erratum.

Edit Sentence 2 to the Following (In Bold): All authors contributed to the study conception and design. Survey preparation and data collection were performed by EF, MJM, and HF. Data analysis and interpretation were performed by MJM and EF, and these authors also drafted the manuscript. TV provided comments on all versions of the manuscript. All authors read and approved the final manuscript.

\begin{abstract}
The original article has been updated.
\end{abstract}
Publisher's Note Springer Nature remains neutral with regard to jurisdictional claims in published maps and institutional affiliations.

The original article can be found online at https://doi.org/10.1007/ s10803-021-05232-0.

Emily F. Ferguson

fergusonef1@gmail.com

1 Koegel Autism Center, University of California Santa Barbara, Santa Barbara, CA 93117, USA 